\title{
幍H90
}

\section{El Museo del Cobre de Cerro Muriano (Córdoba)}

Francisco Penco Valenzuela | director del museo

Daniel Quesada Fernández | historiador del arte

URL de la contribución <www.iaph.es/revistaph/index.php/revistaph/article/view/3841>

\section{RESUMEN}

En julio de 2010 el Museo del Cobre (que en 2002 era anotado preventivamente en el Registro de Museos de Andalucía, quedando inscrito defintivamente en marzo de 2004) se constituía como una de las 21 áreas protegidas del bien de interés cultural con la tipología de sitio histórico de la zona minera de Cerro Muriano (Córdoba), empezaba así a formar parte del Catálogo General del Patrimonio Histórico Andaluz. En la actualidad, es uno de los pocos ejemplos de estas características de la comunidad autónoma andaluza.

\section{Palabras clave}

Cerro Muriano | Cobre | Córdoba (Provincia) | Metalurgia | Minería | Museos | 


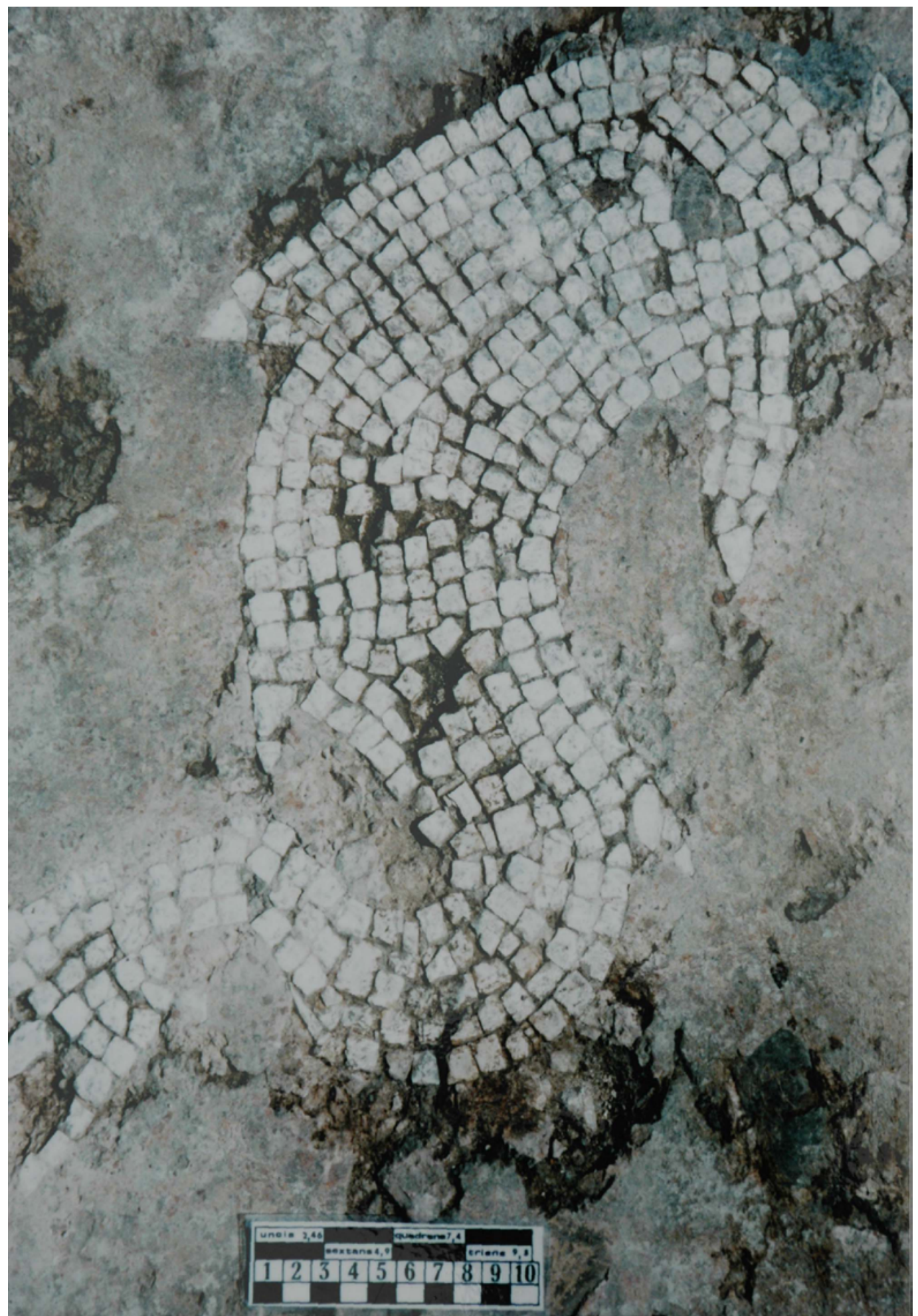

Detalle de mosaico Augusteo, Thermae del Cerro de la Coja. Cerro Muriano (Obejo) | fuente Fondos Museo del Cobre (Fernando Penco Valenzuela) 
Cerro Muriano se encuentra al norte de la provincia de Córdoba, a unos 18 kilómetros de la capital con la que se comunica mediante dos carreteras nacionales: N-432 y N-432A. La actividad minero-metalúrgica desarrollada en esta reserva a lo largo de su historia, se ve en parte representada en el Museo del Cobre, que era anotado preventivamente en el Registro de Museos de Andalucía el 9 de julio de 2002 y que en marzo de 2004 quedaba inscrito definitivamente bajo la denominación con la que se le conoce en la actualidad.

Desde 2010 forma parte del Catálogo General del Patrimonio Histórico Andaluz, como una de las 21 áreas protegidas del bien de interés cultural, con la tipología de sitio histórico, de la zona minera de Cerro Muriano, en los términos municipales de Córdoba y Obejo. Se trata pues, de uno de los pocos ejemplos de esta naturaleza que goza de tal grado de protección, en la comunidad andaluza.

El museo surgirá a raíz de las diversas intervenciones arqueológicas de urgencia llevadas a cabo en uno de sus más emblemáticos yacimientos: el cerro de la Coja. Será a partir del año 2000 cuando en ese lugar se exhumen unas thermae de época Altoimperial y de escasa vida, parte de cuyos materiales serán recuperados e interpretados.

La aparición de ingente cultura material y el deseo de ponerla en valor por parte de las instituciones locales y de diversas asociaciones culturales, destacando la labor de Aes Marianum, provocó que se encargara un proyecto

Ingenieros y accionistas de la Cordoba Copper Company Ltd., a las puertas de Villa Alicia, Cerro Muriano | fuente Museo del Cobre (Colección Pearce, 1909-1912)

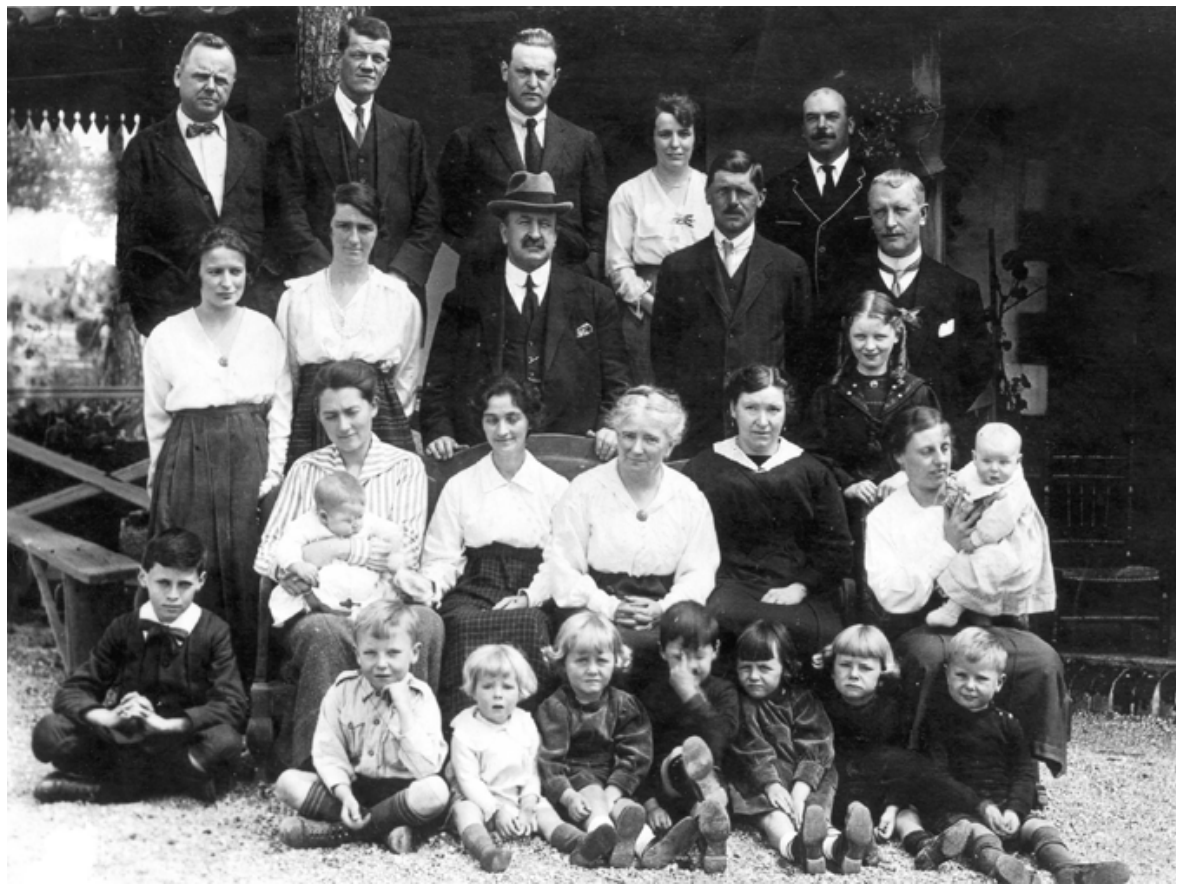


museográfico del que nacería un museo que ya aparece en el plano de población de las minas de Cerro Muriano del Instituto Geográfico y Estadístico de la Provincia de Córdoba (Madrid, 3 de diciembre de 1918) como antigua casa cuartel de la Guardia Civil.

De esa época, y donada al museo por la familia Pearce, se conserva una magnífica panorámica fechada en la década de 1910 en la que se atisba la industria minero-metalúrgica de Cerro Muriano a pleno rendimiento -las chimeneas de los hornos de las fundiciones y lavaderos de la Cordoba Copper Company Ltd. están humeando-y donde aparece el futuro museo.

El edificio, que posee materiales constructivos de época industrial -ladrillo inglés y carbonilla- así como sillares reaprovechados de construcciones romanas, está distribuido en dos plantas y consta de una entrada o recibidor, un despacho de dirección, aseos, un taller de usos múltiples y tres salas expositivas, donde se expone parte de una fértil y larga historia minero-metalúrgica que arranca en el Calcolítico.

En dichas salas se muestran un total de 308 piezas. A la sala I corresponden 57 piezas, 66 a la sala II, y 185 a la sala III. Los metales exhibidos representan un $32 \%$, y la cerámica un 29\%, expresando el protagonismo en las salas de exposición. Complementan el discurso expositivo del museo adornos personales, un amuleto, elementos cerámicos, elementos arquitectónicos, elementos pétreos, elementos suntuarios, objetos de industria pulimentada,

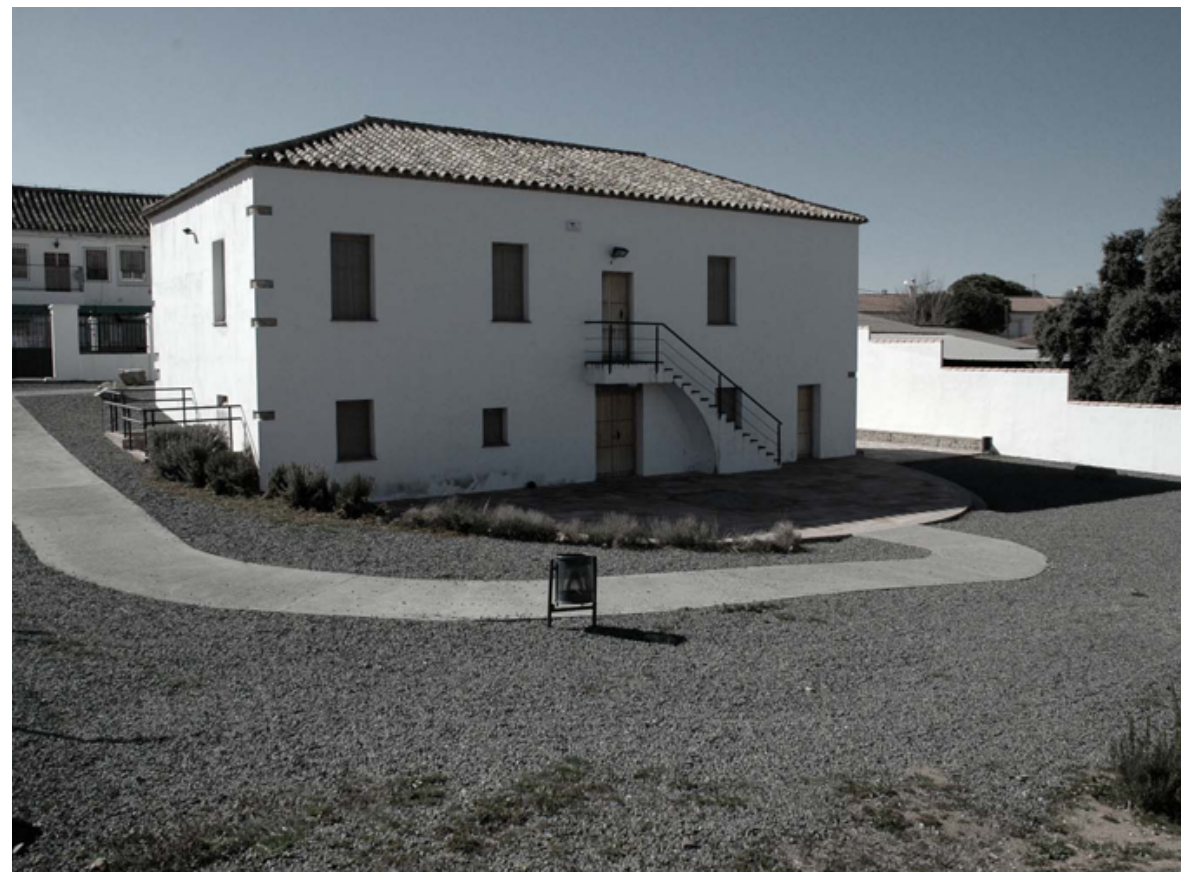

Fachada trasera del Museo del Cobre de Cerro Muriano | fuente Museo del Cobre (Fernando Penco Valenzuela) 


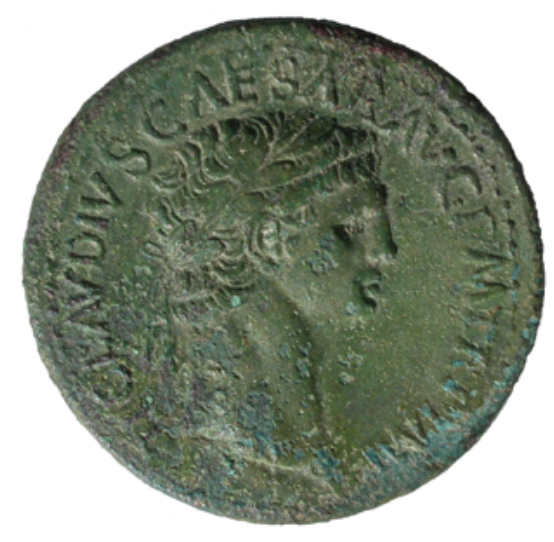

Sestercio de Claudio (41 d. de C.) | foto Museo del Cobre (Ramón Rodríguez Pérez) de industrias líticas, instrumentos de fundición, metales, minerales, piezas numismáticas, piezas sometidas a análisis y elementos de vidrio.

El grueso de la procedencia de las piezas pertenece a la reserva minera de Cerro Muriano (un 72\%), pero el museo cuenta además con materiales originarios de otras zonas geográficas de la provincia de Córdoba y, en menor proporción, de otros territorios nacionales. El total de piezas restauradas ronda el $16 \%$ del total.

La sala I está dedicada a la geología y la metalurgia murianenses y en sus cuatro vitrinas, además de los minerales más importantes de sus yacimientos de cobre, pueden observarse de cerca ciertas piezas que han sido sometidas a análisis metalográficos y metalogenéticos. Algunas de ellas están relacionadas con el fascinante proceso de conversión del mineral en metal: lingotes de cobre, escorias de fundición, clavos de hierro, etc.

En la sala II, dedicada a la Prehistoria y Protohistoria, el visitante puede contemplar los objetos más antiguos de la colección -algunos de ellos con más de 4.500 años-; por orden cronológico, se pueden encuadrar en los períodos: Calcolítico, Edad del Bronce y Edad del Hierro.

El último espacio expositivo, la sala III, sumerge al espectador en Roma y en sus diferentes fases: es el mayor de los espacios y el que contiene más objetos. En sus vitrinas pueden verse buena parte de los materiales descubiertos en las excavaciones de las termas del cerro de la Coja junto con otras piezas de cultura material, procedentes de diversas prospecciones e intervenciones arqueológicas practicadas en la zona.

A las espaldas del edificio del museo, dentro del terreno perteneciente al mismo, se encuentra uno de los hornos romanos más antiguos de la Bética, fechado en la época republicana. Fue trasladado hasta las dependencias del museo, desde el yacimiento de los Pinares, en el año 2002. 


\section{BIBLIOGRAFÍA}

- CANO SANCHIZ, J. M. (2012) La minería y la metalurgia del cobre como elementos de industrialización: análisis arqueológico del complejo británico de Cerro Muriano (Córdoba). Tesis Doctoral, Universidad de Córdoba, 2012

- CRIADO PORTAL, A. J.; PENCO VALENZUELA, F. (1999) Una propuesta de Proyecto de Intervención Arqueológica de Urgencia y Prospección superficial en el entorno minero de Cerro Muriano (Córdoba). Antiquitas, 10, 1999 , pp. $195-204$

- CRIAdO PORTAL, A. J.; PENCO VAlENZUELA, F. (2002) Tres piezas metálicas descontextualizadas procedentes del complejo arqueológico de Cerro Muriano (Córdoba): Relación isotópica del plomo y otros aspectos. Antiquitas, 14, 2002, pp. 9-20

- DECRETO 352/2010, de 27 de Julio, por el que se inscribe en el Catálogo General del Patrimonio Histórico Andaluz como Bien de Interés Cultural, con la tipología de Sitio Histórico, la zona Minera de Cerro Muriano, en los términos municipales de Córdoba y Obejo. Boletín Oficial de la Junta de Andalucía, n. ${ }^{\circ}$ 149, 30 de julio de 2010, pp. 47-72

- HERNANDO FERNÁNDEZ; J. L.; HERNADO LUNA, R. (1998) Yacimientos filonianos de cobre, explotaciones mineras y establecimientos metalúrgicos del Cerro Muriano (Córdoba). Boletín de la Real Academia de Córdoba de Ciencias, Bellas Letras y Nobles Artes, 135, 1998, pp. 145170

- PENCO VAlENZUELA, F. (2004) Las thermae públicas del yacimiento del Cerro de la Coja: resultados preliminares de la intervención arqueológica de urgencia en el yacimiento de Cerro Muriano (Obejo). Anuario arqueológico de Andalucía 2001, 3, Tomo 1 (Actividades de urgencia), 2004 pp. 297-316

- Penco VAlenzuela, F. et ál. (2007) Memoria justificativa de la documentación técnica para la inclusión en el Catalogo General de Patrimonio Histórico Andaluz de los lugares vinculados al patrimonio arqueológico-industrial de la zona minera de Cerro Muriano (Córdoba-Obejo). Delegación Provincial de Cultura de Córdoba, 2007

- PEnco VAlenzuela, F. (2007) Acerca de la minería del cobre en Cerro Muriano y de la aprobación de un planeamiento urbanístico desproporcionado. De re metallica (Madrid): revista de la Sociedad Española para la Defensa del Patrimonio Geológico y Minero, 8, 2007, pp. 37-48

- QUESADA FERNÁNDEZ, D. (2015) Análisis y valoración actual del paisaje y patrimonio industrial de Cerro Muriano (Córdoba). Trabajo fin de Máster inédito (Máster universitario en Educación y Museos: patrimonio, identidad y mediación cultural), Universidad de Murcia, 2015 